\title{
AGILE PRODUCT DEVELOPMENT: FEATURES IDENTIFICATION AND APPLICATION IN THE ELECTRICITY SECTOR
}

\author{
Ribeiro, Artur Tavares Vilas Boas (1); Leal, Lorenna Fernandes (1); do Amaral, Guilherme \\ Soares Gurgel (2); Kahn, Ricardo (2); Pacci Evaristo, Bruno Guilherme (3); Romão, Victor (3); \\ G Altmann, Ricardo (3); R Avó, Marcos (3); Salerno, Mario Sergio (1); Plonski, Guilherme Ary \\ (1); Zancul, Eduardo (1)
}

1: University of Sao Paulo; 2: ISA CTEEP; 3: Lunica

\begin{abstract}
The electricity sector is in the midst of a structural change driven by new technologies. In Brazil, the electricity sector regulation has mechanisms to foster innovation, including investments in R\&D. Recently, the regulatory agency and the industry have been calling for approaches to increase the rate at which R\&D departments generate solutions that end up being adopted. As a result, novel approaches to R\&D project management have entered the agenda. In this context, the objective of this paper is to characterise Agile Product Development and its application in a highly regulated sector. The paper presents a systematic literature review with the debates about Agile and new product development. Then, a case study exploring an early adoption of the Agile approach in R\&D project management in the Brazilian electricity sector is presented. Results include the identification of the Agile features most frequently mentioned in the literature. Moreover, the case study explores the Agile features that were more easily absorbed in early adoption, such as iterative patterns, and discusses implementation challenges in team structure, feedback loops, and communication.
\end{abstract}

Keywords: New product development, Lean design, Design process, Case study

\section{Contact:}

Zancul, Eduardo

University of Sao Paulo

Departamento de Engenharia de Produção

Brazil

ezancul@usp.br

Cite this article: Ribeiro, A.T.V.B., Leal, L.F., do Amaral, G.S.G., Kahn, R., Pacci Evaristo, B.G., Romão, V., G Altmann, R., R Avó, M., Salerno, M.S., Plonski, G.A., Zancul, E. (2019) 'Agile Product Development: Features Identification and Application in the Electricity Sector', in Proceedings of the 22nd International Conference on Engineering Design (ICED19), Delft, The Netherlands, 5-8 August 2019. DOI:10.1017/dsi.2019.221 


\section{INTRODUCTION}

The evolution of the electricity sector has been influenced by novel technologies, driven by trends as decarbonisation, digitalisation, and decentralisation referred to as the three Ds (Di Silvestre et al., 2018). The emergence of new technologies - such as more powerful energy storage systems, decentralised distribution networks, and new sources for capturing energy - are drawing attention to innovation and new product development.

The Brazilian electricity sector- meaning generation, transmission, and distribution of electric energy faces the following limitations in its R\&D practices: (i) unstructured R\&D processes, (ii) lack of alignment between R\&D and the company's strategy, (iii) partnerships being developed in an informal way, (iv) incremental mindset and short-term focus, (v) lack of well trained and motivated project managers, and (vi) theoretical projects rather than technologies being applied within the market (Carvalho, Santos and Barros Neto, 2013). Worldwide there is a similar understanding that R\&D efforts in energy should be improved to overcome challenges on early-stage technologies and its widespread absorption (Sagar and Van der Zwaan, 2006). In addition, the Brazilian electricity sector faces regulatory pressures that impact compliance requirements and investment commitments in $\mathrm{R} \& \mathrm{D}$ projects.

In parallel, there is an increasing debate surrounding the application of Agile approach for improvements on product development performance at industrial contexts (Cooper, 2016; Sommer et al., 2015), as well as its application in regulated sectors (Fitzgerald et al., 2013), including cases of managing product development within the electricity sector (Sommer et al., 2015). Although evidence shows growing interest from the industry and academia about expanding Agile application to new fields, there are open questions in the literature and practice. For this study, we sought to answer this main question: which are the most frequent features in Agile Product Development literature and how do they fit in a context of R\&D in regulated sectors?

Thus, the objective of this paper is to characterise Agile Product Development and its application in a regulated sector. Within this objective, the paper presents a systematic literature review with the debates about Agile and New Product Development. In addition, a case study exploring the early adoption of the Agile approach in R\&D project management in the Brazilian electricity sector is presented.

The paper is organised as follows. Section two presents recent discussions around Agile approach for managing Product Development. Section three presents the systematic literature review on Agile Product Development. In the fourth section, we focus on the case study and its relations with the theory. The paper closes in the fifth section, with the final remarks of the study.

\section{THEORETICAL FRAMEWORK: AGILE APPROACH WITHIN INDUSTRIAL AND REGULATED ENVIRONMENTS}

The debate around the Agile approach began in the 1990s in the context of software development projects, culminating in the Agile Manifesto in 2001 and a number of other discussions on the quest for greater agility in organisational processes (Conforto et al., 2016). Although more widespread in the software development, authors have been pointing to Agile application in other contexts, such as managing product development in industrial environments (Cooper, 2016; Sommer et al., 2015). Serrador and Pinto (2015) emphasise the main premise behind this emergence: even though good practices of traditional project management were implemented, failure rates remained high and projects continued to be delivered without meeting customer expectations or keeping up with market dynamics.

In the Agile Manifesto (Beck et al., 2001), a new management model was proposed based on: (i) an iterative and open to change approach; (ii) routines for alignment and delivery rhythm; (iii) a culture of autonomous and motivated people. This was the response to criticisms of old models with an excess of standardisation, documentation and static plans defined at the beginning of the project with little margins for change.

In their literature review on Agile within the context of project management, Conforto et al. (2016) present a conceptual definition for the "agility" construct: "Agility is the project team's ability to quickly change the project plan as a response to customer or stakeholders needs, market or technology demands in order to achieve better project and product performance in an innovative and dynamic project environment." (p. 667). 
Cooper (2016) underlines the growth in the adoption of the Agile approach and its spill over to environments outside IT, including an Agile-Stage-Gate hybrid model, in which projects related to the development of new physical products rely on the go/kill decisions, but also with the flexibility and responsiveness of the Agile approach. The author, along with Sommer et al. (2015), presents the Scrum method as the most popular of the Agile implementation in the context of physical products.

According to Sommer et al. (2015), the Scrum method achieves agility through organising processes based on short cycles: 2-4 weeks sprints aimed at developing pre-defined features (sprint backlogs) of a larger project (product backlog). Within the sprints, there is a 15 minutes daily meeting to align the planned tasks to be performed and pending tasks to be resolved. The authors propose an adaptation of Scrum next to the Stage-Gate - called "industrial scrum" -, which involves: (i) execution teams based on the short cycles framework; (ii) strategic and portfolio coordination teams accompanying the project development through stage-gate; (iii) an early-stage feasibility study in which "the product goes through a mini version of all the product development stages just after initial idea development" (p. 42).

An important aspect of the work of Sommer et al. (2015) for the context of this paper is the fact that one of the study's case is from a cross-country power cables company, usually characterised by greater regulation and rigidity in product development processes. Moreover, since the Brazilian electricity sector is intensively regulated, we sought the theoretical subsidy in the work of Fitzgerald et al. (2013), which presents a framework of Agile approach for regulated environments - but exclusively for software products. In their viewpoint, an Agile approach can be undermined by issues of regulated environments, such as excessive process control, standardisation, traceability, auditing, and rigid specification. This vision is reinforced by the PSI Framework (Reich and Subrahmanian, 2017), based on the premise that product development is a "complex activity that takes place within a rich context of interacting conditions" (Subrahmanian et al., 2017. p. 232), subject to institutional, organizational and individual factors influences. In response to the regulative pressures to Agile development, Fitzgerald et al. (2013) present a Scrum implementation case that adds elements which ensure regulatory requirements while maintaining the team's flexibility and autonomy. It includes a toolset that allows continuous compliance and living traceability, as well as a governance structure that involves regulatory requirements in a fast and unobtrusive way. For both regulated sectors and the original industrial Scrum context, the role of governance - with clear figures for project management (Scrum Master), customer representation (Product Owner) and strategic management (Product Sponsor) - is emphasised.

\section{SYSTEMATIC LITERATURE REVIEW: CHARACTERISING AGILE NEW PRODUCT DEVELOPMENT}

Considering the goal of the paper, to explore the concept of Agile product development, a systematic literature review was carried out to identify the main elements of Agile product development. To that end, a content analysis approach was chosen because it "allows the identification of the most important topics, approaches and methods, as well as the most important definitions of a theme" (Carvalho, Fleury and Lopes, 2013, p.1.419).

As a first step, an initial search on Web of Science database for articles or reviews in peer-reviewed journals with no time frame limitation was performed, using the strings: ("product development" OR "new product development" OR "NPD" OR "PDP") AND ("agility" OR “Agile"). A total of 203 entries were found. To narrow down the sample, the first exclusion criteria used was the keywords. For the first and second keywords of each paper, the strings "product development", "agility" and "Agile" were applied as a filter, resulting in 75 documents. Additionally, the papers not included by the keywords filter had their titles read, and 37 documents were added to the sample because they indicated similarity to the topic, resulting in 112 documents.

Subsequently, a snowball approach was applied using Vosviewer software to identify the most cited papers on the previous 112 sample documents. From the co-citation analysis, which groups the documents in clusters based on the times they are cited together, it was possible to identify two main clusters. One focused on Agile manufacturing, and the other focused on Agile software development and its derivatives. Even though they share a common philosophy, as to respond to a dynamic environment through flexible processes (Leite and Braz, 2016), the papers on Agile manufacturing aim to encompass the whole company, and not only the product development process. Since Agile 
manufacturing comprehends an aggregated and broader view on the firm level, including aspects such as supply chain integration, operations, financial and strategic planning (Ghobakhloo and Azar, 2018), and does not discuss deeper the product development processes (the main focus of the present Case Study). Thus, the documents on Agile manufacturing (12 in total) were removed from the sample. In addition, through the snowball approach, 6 documents were included. Then, the remaining 106 papers had their abstracts read, and 37 papers were selected for content analysis due to their relation to this paper focus.

The main goal of the content analysis was to identify consensus over agile features in the literature, through the analysis of the most frequently mentioned features of Agile product development, as part of the characterisation effort for Agile approaches and its subsequent application in a regulated sector. From the 37 remaining articles, 5 are not accessible, and 10 of them only mention but don't deeply describe Agile product development. The remaining 22 articles present descriptions and features of Agile approaches. However, 7 of these articles were written either by Sommer or Cooper, concerning Stage-gate hybrids. Then, from these 7 articles, the one considered the most relevant in terms of describing the agile features from their point of view was maintained, and the other 6 were removed, resulting in 16 articles as the final sample. The features were listed and their occurrence in the papers were counted regarding the number of documents that mention the feature, as Table 1 shows:

Table 1: Agile features from literature and its frequency.

\begin{tabular}{|c|c|c|c|c|c|c|c|c|c|c|c|c|c|c|c|}
\hline 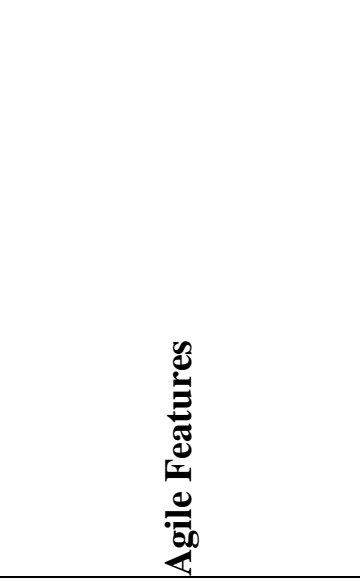 & 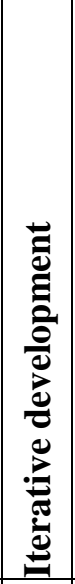 & 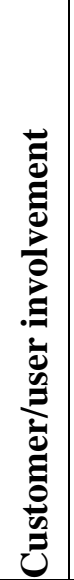 & & 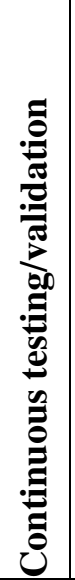 & 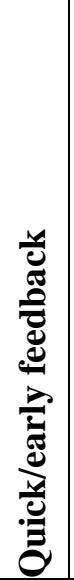 & 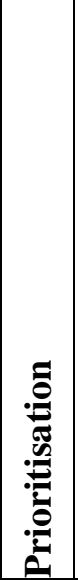 & 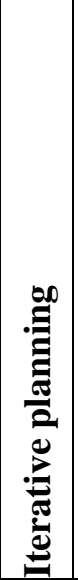 & 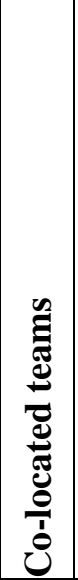 & 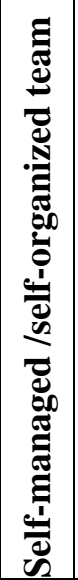 & 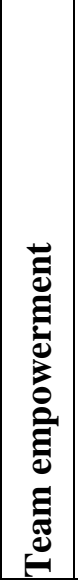 & 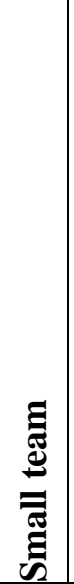 & 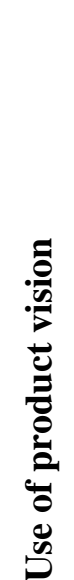 & 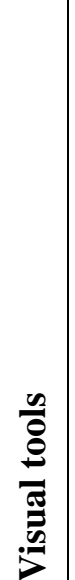 & 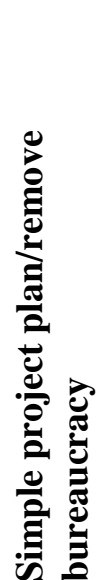 & 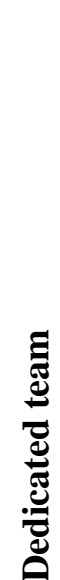 \\
\hline $\begin{array}{c}\mathrm{n} \text { (occurrence in \# of } \\
\text { papers) }\end{array}$ & $\because$ & 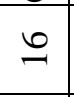 & $\simeq$ & 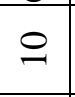 & $\varrho$ & $\infty$ & $\infty$ & $r$ & $r$ & 0 & 6 & 6 & $\gamma$ & + & $m$ \\
\hline$\%$ (of studied papers) & $\begin{array}{l}\check{D}^{\circ} \\
8 \\
0\end{array}$ & 兽 & $\stackrel{8}{i}$ & $\stackrel{8}{0}$ & $\stackrel{8}{0}$ & $\begin{array}{l}0 \\
0 \\
0\end{array}$ & 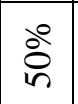 & \begin{tabular}{|l|l}
\multirow{8}{*}{} \\
\multirow{8}{*}{}
\end{tabular} & 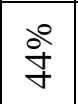 & \begin{tabular}{|l|}
0 \\
$\infty$ \\
$\infty$
\end{tabular} & $\begin{array}{l}\infty \\
\infty \\
\infty\end{array}$ & 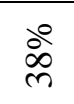 & 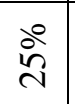 & 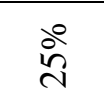 & $\stackrel{\circ}{2}$ \\
\hline $\begin{array}{l}\text { Karlstrom and } \\
\text { Runeson (2005) }\end{array}$ & $\mathrm{x}$ & $\mathrm{x}$ & $\mathrm{x}$ & & $\mathrm{x}$ & $\mathrm{x}$ & & & & $\mathrm{x}$ & & & & & \\
\hline $\begin{array}{l}\text { Pikkarainen and } \\
\text { Passoja (2005) }\end{array}$ & $\mathrm{x}$ & $\mathrm{x}$ & & & $\mathrm{x}$ & $\mathrm{X}$ & $\mathrm{x}$ & & $\mathrm{x}$ & & & & & $\mathrm{x}$ & \\
\hline $\begin{array}{l}\text { Dyba and Dingsoyr } \\
(2008)\end{array}$ & $\mathrm{x}$ & $\mathrm{x}$ & $\mathrm{x}$ & $\mathrm{X}$ & $\mathrm{x}$ & & & & & & $\mathrm{x}$ & & & & \\
\hline Conboy (2009) & $\mathrm{x}$ & $\mathrm{x}$ & & & & $\mathrm{x}$ & & $\mathrm{x}$ & & & & & & & \\
\hline Dingsoyr et al. (2012) & $\mathrm{x}$ & $\mathrm{X}$ & $\mathrm{X}$ & $\mathrm{x}$ & & & & $\mathrm{x}$ & $\mathrm{X}$ & $\mathrm{x}$ & & & & $\mathrm{x}$ & \\
\hline $\begin{array}{l}\text { MacCormack et al. } \\
(2012)\end{array}$ & $\mathrm{x}$ & $\mathrm{x}$ & $\mathrm{x}$ & $\mathrm{X}$ & & $\mathrm{X}$ & $\mathrm{X}$ & & & & & $\mathrm{x}$ & & & \\
\hline Grimheden (2013) & $\mathrm{x}$ & $\mathrm{x}$ & $\mathrm{x}$ & $\mathrm{x}$ & $\mathrm{x}$ & & & & $\mathrm{x}$ & $\mathrm{x}$ & & & & & \\
\hline Conforto et al. (2014) & $\mathrm{x}$ & $\mathrm{x}$ & $\mathrm{x}$ & $\mathrm{x}$ & & & $\mathrm{x}$ & $\mathrm{x}$ & $\mathrm{x}$ & $\mathrm{x}$ & $\mathrm{x}$ & $\mathrm{x}$ & $\mathrm{x}$ & $\mathrm{x}$ & $\mathrm{x}$ \\
\hline Chuang et al. (2014) & $\mathrm{x}$ & $\mathrm{x}$ & & & $\mathrm{x}$ & & & & & & & & & & \\
\hline Smith (2008) & $\mathrm{x}$ & $\mathrm{x}$ & $\mathrm{x}$ & $\mathrm{x}$ & $\mathrm{x}$ & $\mathrm{x}$ & $\mathrm{x}$ & $\mathrm{x}$ & & & $\mathrm{x}$ & $\mathrm{x}$ & & & \\
\hline $\begin{array}{l}\text { Conforto and Amaral } \\
\text { (2016) }\end{array}$ & $\mathrm{x}$ & $\mathrm{X}$ & & $\mathrm{x}$ & & $\mathrm{x}$ & $\mathrm{X}$ & $\mathrm{X}$ & $\mathrm{x}$ & & $\mathrm{x}$ & & $\mathrm{x}$ & $\mathrm{x}$ & $\mathrm{x}$ \\
\hline $\begin{array}{l}\text { Cooper and Sommer } \\
(2016) b\end{array}$ & $\mathrm{x}$ & $\mathrm{x}$ & $\mathrm{X}$ & $\mathrm{x}$ & $\mathrm{X}$ & $\mathrm{X}$ & $\mathrm{X}$ & $\mathrm{x}$ & $\mathrm{x}$ & $\mathrm{x}$ & $\mathrm{x}$ & & $\mathrm{x}$ & & $\mathrm{X}$ \\
\hline
\end{tabular}




\begin{tabular}{|l|c|c|c|c|c|c|c|c|c|c|c|c|c|c|c|}
\hline Schon et al. $(2017)$ & $\mathrm{x}$ & $\mathrm{x}$ & $\mathrm{x}$ & & & & $\mathrm{x}$ & & $\mathrm{x}$ & & & $\mathrm{x}$ & & & \\
\hline Tura et al. $(2017)$ & $\mathrm{x}$ & $\mathrm{x}$ & $\mathrm{x}$ & & $\mathrm{x}$ & & & & & & $\mathrm{x}$ & & & & \\
\hline $\begin{array}{l}\text { Giorgadze } \text { et al. } \\
(2017)\end{array}$ & $\mathrm{x}$ & $\mathrm{x}$ & $\mathrm{x}$ & $\mathrm{x}$ & $\mathrm{x}$ & & $\mathrm{x}$ & & & & & $\mathrm{x}$ & & & \\
\hline Waldron (2017) & $\mathrm{x}$ & $\mathrm{x}$ & $\mathrm{x}$ & $\mathrm{x}$ & $\mathrm{x}$ & $\mathrm{x}$ & & $\mathrm{x}$ & & $\mathrm{x}$ & & $\mathrm{x}$ & $\mathrm{x}$ & & \\
\hline
\end{tabular}

Some of the features listed are mentioned in the papers using different wording. For example, iterative development is mentioned as iterations, sprints, loops, fast increments, short time increments, etc. Prototyping includes delivering working software in case of software development, and prototypes, designs, products, in case of physical products. Papers that adopted the broader view of product development, (Conforto et al., 2014; Cooper and Sommer, 2016b; Grimheden, 2013; MacCormack et al., 2012) would generally cite prototype or related terms. Test continually and continuous validation are considered similar and are grouped, as well as customer involvement and managing customer demands, and also remove waste/bureaucracy and simple project plan/processes/ documents.

As an overview, two main topics can be identified from the agile features extracted from the sample. The project team, which includes: co-located teams, team empowerment, dedicated team, small team, self-managed /self-organized team and visual tools. The second item is project management style and approach: iterative development, customer/user involvement, prototyping, continuous testing/validation, quick/early feedback, prioritisation, iterative planning, use of product vision, simple project plan/remove bureaucracy. At one hand, there is an effort to create a team that can work closely together, does not need supervising and feel empowered to make decisions along the project. On the other hand, there's an attempt to avoid the pre-defined rigid scope of traditional project management, keeping it flexible; to bring the customer to participate actively in the development process, prioritizing what maximizes value for the customer; and to create a pace of development that can grant speed to the process.

The most frequent features in the literature, which are a consensus among the authors, are iterative development and customer/user involvement. Prototyping, continuous test/validation and quick/early feedback are also frequent in the literature. These elements would generally come together or in a combination of these terms, as a cycle of iterative development and testing with the customer/user, as highlighted by Conforto et al. (2014, p.24):

This practice, called iterative planning is in line with one of the fundamental principles of APM (Agile Project Management) theory, in other words, iterative development or the rapid and continuous delivery of parts of the product (...), thereby obtaining continuous feedback from the customer to be able to respond to constant changes in requirements, needs, risks, new opportunities, and so forth.

The team structure is discussed in half of the papers. The most relevant features are co-located, empowered, dedicated and self-organized teams. Collaboration is mentioned in 55\% of the papers but was not included in the table because it represents a general feature and not a specific characteristic. Other broader features as flexibility, adaptation and responsiveness are also mentioned. The Agile Manifesto is cited as a reference in $63 \%$ of the documents.

Since Agile approaches initially focused on software development, they were not completely applicable to broader product development projects. Adaptations were necessary, and companies merged a few Agile features to their traditional product development processes, resulting in hybrid approaches (Conforto et al., 2014; Sommer et al., 2015; Cooper and Sommer, 2016a). Hence, the most widespread traditional approach for product development is Stage-gate (Cooper, 2016) and the most common Agile hybrid approach in the sample literature is the Agile Stage-gate, that merges the traditional approach with Scrum method (Cooper, 2016). Cooper and Sommer have been continuously and systematically discussing this topic (Cooper, 2014; Sommer et al., 2015; Cooper, 2016; Cooper and Sommer, 2016a; Cooper and Sommer, 2016b; Cooper, 2017; Cooper and Sommer, 2018).

\section{CASE STUDY: IMPROVING R\&D OUTPUTS THROUGH AGILE PRODUCT DEVELOPMENT IN A REGULATED SECTOR}

The case study discusses the application of Agile for managing an R\&D project within a regulated context, the Brazilian electricity sector. The project aims the development of new solutions related to the maintenance, installation and monitoring of transmission lines using drones (associated with 
cameras, computer vision and flight automation). From a methodological point of view, it is considered a pilot project in incorporating Agile principles in the sector.

The project involves three stakeholders: one of the largest transmission companies in Brazil, which handles around 25\% of Brazilian transmitted energy and has a transmission share of $99 \%$ in the State of São Paulo, Brazil's wealthiest state; one research laboratory from a leading Brazilian university; and one Brazilian startup focused on application, commercialisation and maintenance of drones. The research lab focuses on the development of software and artificial intelligence technologies for computational vision and flight automation, while the drone startup is running multiple tests in the field and collecting images and other kinds of data for improving the technology. The research lab and the drone startup are external R\&D partners to the electricity company. The electricity company has a few employees involved in the R\&D project: an innovation manager, an executive and personnel from the maintenance department. The company also plays the role of a project client and hired a senior executive as a project manager.

The company executives have reasoned that $R \& D$ processes had not followed contemporary approaches adopted by startups - such as the "lean startup mindset" (Ries, 2011), which is based on running short cycles of product development seeking to validate hypothesis about the solution together with customers in a fast and responsive way. According to the creator of the Lean Startup concept, his approach was inspired bythe Agile principles of iterative development (Ries, 2017).

The implementation of Agile features in the R\&D project was organized as follows: first, the R\&D external partners, along with the transmission company personnel, went through an initial exploration exercise to think of different applications and challenges (divergent thinking) and also to execute early-stage technology tests. After achieving a better understanding of the needs and aligning the possibilities, expectations and regulatory constraints, the target was developed around a project vision definition - more framed and goal oriented. The company executives (the project customers) reinforced Agile principles, such as the avoidance of a strict plan, and the product being developed through an iterative process based upon short cycles of development with quick feedback.

These first defined Agile features were implemented within routines of weekly follow up meetings with the project manager, monthly meetings with the transmission company executives, and constant iterations along with maintenance personnel (the product/solution final users). Also, every three months there is a formal presentation of results including high-level executives from the client. The project, still ongoing, was reported to have, so far, delivered more effective results - solutions with a better fit with the business and more "implementable".

The case study relied on multiple sources of data. The data collection was conducted through four indepth non-structured interviews, three executive meetings, one workshop participation and two debrief meetings. Data were collected during the project timeframe. The personnel included in the in-depth interviews consisted of: (i) a managing partner from the drones startup ( 150 minutes); (ii) the research coordinator from the academic laboratory ( 100 minutes); (iii) the project manager $(\sim 150$ minutes); (iv) a technician from the transmission company that is responsible for following the R\&D project ( $\sim 70$ minutes). The executive meetings were part of the Agile monthly follow-up routines, being 90 to 120 minutes meetings with all stakeholders - the transmission company executives, the drones' startup executives and the researchers from the university laboratory. The workshop was held by the transmission company and it was aimed at disseminating the best practices for applying drones in the electricity sector, with activities and discussions involving other electricity companies, regulators, the drone startup and the researchers from the university partner. Notes were taken throughout all these interactions, and, seeking more research reliability, two debriefing meetings - one between the researchers and other together with the transmission executives - were held to analyse data from multiple investigators (Eisenhardt, 1989).

After data gathering, a comparison was made to better understand the relationship between what was found in the systematic literature review and the case study collected data. Given that the project execution occurred independently of the literature review, some features identified in the review were not found in the case (and some were partially found). Among the 15 features found in the literature, 11 were identified in the case studied: (i) Iterative development; (ii) Customer / user involvement; (iii) Quick feedback; (iv) Prototyping; (v) Continuous testing / validation; (vi) Iterative planning; (vii) Prioritisation; (viii) Team empowerment; (iv) Use of product vision; (x) Simple project plan / remove bureaucracy. Table 2 presents such points and the evidence found with the data analysis. 
Table 2. Comparison between the systematic literature review findings and the case study findings on Agile features.

\begin{tabular}{|c|c|}
\hline $\begin{array}{l}\text { Agile Features } \\
\text { in the Litera }\end{array}$ & Evidence \\
\hline $\begin{array}{l}\text { Management Features } \\
\text { (Iterative development; } \\
\text { Customer } \\
\text { involvement; } \\
\text { Prototyping; } \\
\text { Continuous testing; } \\
\text { Quick/Early feedback; } \\
\text { Prioritisation; Iterative } \\
\text { planning; Product } \\
\text { vision) }\end{array}$ & $\begin{array}{l}\text {-Constant meetings centred on gathering feedback from executives; } \\
\text {-A new application was developed beyond the planned as a result of } \\
\text { feedback from an iteration; } \\
\text {-Exercises of customer understanding and everyday routines with users; - } \\
\text { The transmission company allocated one employee from maintenance in } \\
\text { the project to offer feedbacks and constantly engage with the partners; } \\
\text {-More than } 20 \text { different applications were tested during one year in a } \\
\text { series of "structured tests" together with the customer; } \\
\text {-Monthly meetings were held for prioritization, but there are complaints } \\
\text { from parts involved that the feedback was not always homogeneous; } \\
\text {-The project had a "activities backlog" document that evolved monthly } \\
\text { with new plans of execution and product improvement. } \\
\text {-Project vision defined, but not completely communicated and lacking } \\
\text { clarity; }\end{array}$ \\
\hline $\begin{array}{l}\text { Team Features } \\
\text { (Self- } \\
\text { managed/organized } \\
\text { teams; Small team; } \\
\text { Simple project plan / } \\
\text { remove bureaucracy) }\end{array}$ & $\begin{array}{l}\text { - The main team is relatively small (around four people), but overall there } \\
\text { were several external partners involving a relatively big number of } \\
\text { stakeholders (two partners and multiple customer departments); } \\
\text {-In comparison to a regular R\&D for the sector in Brazil, it could be } \\
\text { considered to have lower bureaucracy, but not overall. } \\
\text {-Partners had open access to the maintenance employee allocated, to } \\
\text { gather feedback and test independently and without prior permission } \\
\text { from executives. No detailed planning/schedule was required. }\end{array}$ \\
\hline
\end{tabular}

As presented in the table above, the data indicate that several Agile features were more easily implemented than others. This R\&D project has shown that the company was able to implement features related to intensive iteration with the customer, developing products through constant feedbacks, prototyping, prioritisation routines and continuous validation. Comparing with the systematic literature review, those features are the most frequent in the literature. Nevertheless, interviewers from the R\&D partners expressed a hazy comprehension of the product vision. Features related to structuring and managing teams, such as small and dedicated teams, team empowerment, communication through visual tools and removing bureaucracies for team productivity have had limited use in the case. In the interviews with the R\&D partners, it became clear that this non-implementation was due to the project structure based on multiple external partners and a lack of clarity regarding the role of the project manager. The 'self-managed team' being partially observed was due to this confusion around the role of the project manager, with loose teams not reporting project advancements in a systematic way. The hypothesis here is that, since most of the R\&D projects in Brazilian electricity sector happen to be with external partners and companies are cautious to regulatory risk avoidance, some elements of autonomous and collaborative teams may not be completely well suited.

Compared to the traditional strict planned project management approach of $R \& D$ in the Brazilian electricity sector, there were three main improvements of using Agile features: (i) an increase in the rate of task accomplishment; (ii) new applications fronts being developed; (iii) more alignment between the partners and contractors.

The increased rate of tasks accomplished by $R \& D$ partners was highlighted in three of the four interviews. One example was the fact that a traditional $R \& D$ project would test only one application in a long-term research effort, while in the Drone Case they tested 21 applications with short cycles of iterative development. The electricity company also had one maintenance employee with $50 \%$ of its time allocated to the project, being able to offer quick feedbacks and create new opportunities of testing solutions and applications.

The emergence of new applications front was one event emphasised in interviews: a new application was developed beyond what was planned due to iterative processes. In this aspect, interviewers highlighted the trustful relationship that was created allowed teams to be more innovative and result 
oriented, not limiting their works to project scopes and pre-planned deliverables. This outcome was presented as a consequence of the autonomy that was given to the partners to talk and validate assumptions directly with the maintenance personnel.

Third, the initial exploration exercise allowed a "two-sided" alignment: the company understood the technological possibilities and frontiers; the R\&D partners understood the main motivations, expectations and regulatory challenges of its sponsor - an output that minimises the regulatory risks. One example was the interest of executives in drones with "infinite flight" capabilities (drones with autonomous capabilities to find recharging spots along the transmission lines fields), a bold idea that was discarded within the first exploratory exercises. Besides regulatory risks, agile features that emphasise iteration and constant meeting were helpful in guaranteeing more alignment from all of the involved stakeholders, which created a better environment for dealing with compliance challenges (e.g.: partners were constantly requested to document their advances and to be careful with risks).

Some challenges remain to be explored. For example, scope variability affecting pre-defined budgets by R\&D partners who were not used to the new iterative model. Another perceived point was that, by emphasising technology implementation through short cycle iterative processes, the transmission company decision makers began to pay more attention to short-term applications possibilities - and longer-term research topics might have been deprioritised, which indicates potential challenges that gatekeepers may face when adopting Agile principles. Some issues were also identified on governance, with several stakeholders involved affecting the flow of information and project management, generating questions for the partners about who to report to, who to validate with and other interactions. Despite these challenges, the interviews and interactions with participants expressed an improvement in results and technological absorption possibilities by the transmission company, which indicates that the adaptation of Agile approaches and principles in the specific project has been effective.

\section{FINAL REMARKS}

This paper aimed to characterise Agile Product Development and understand its application in a regulated sector. Through the systematic literature review together with the case study, it was possible to identify Agile main characteristics. These characteristics can be organised in four topics: (i) iterative development with short cycles and fast feedback; (ii) customer/user involvement; (iii) autonomous, collaborative / co-located and dedicated teams; (iv) flexible product development, oriented towards an open (and larger) vision rather than a stricter plan.

This paper contributes to the current research by organising the main features cited in Agile Product Development literature. It confirms the findings of Cooper and Sommer (2018) on Agile features improving the rate of deliverables, and goes beyond highlighting challenges that arise, such as governance and prioritisation. Together with the case study, it also contributes to the work of Fitzgerald et al. (2013) in offering a new perspective of Agile approaches for regulated sectors beyond software development.

For practitioners, the study may be valuable by noticing how Agile approaches can lead to an increased rate of task accomplishment, effective solutions and alignment with the R\&D contractor. It was also observed that Agile features can be implemented by a company in its early-stage experiments, such as the features related to iterative development with customer/user engagement. In addition, the governance challenges expressed in the interviews reinforce the importance of having routines and clear roles/positions for implementing Agile principles, especially in industrial and regulated sectors, as pointed out in the works of Sommer et al. (2015) and Fitzgerald et al. (2013). Using Agile features, such as constant meetings and quick feedbacks showed to be helpful in dealing with compliance due to better alignment and documentation.

For the Brazilian electricity sector, using Agile to manage R\&D projects may help in overcoming the challenges presented by Carvalho, Santos and Barros Neto (2013), guaranteeing better managerial structure, increased alignment with the corporate strategy, more innovative outputs and technologies being brought from research centres to real application. It also may provide opportunities for new players (such as startups) to participate actively in such kinds of projects. It could be contradictory to assert that Agile features, usually related to less structure and more autonomy, promoted more structure and alignment, but the case showed that iterative processes helped in creating enhanced management control due to better information exchange and constantly improving the development plan. 
For future studies, the main challenges found in the case study could be explored, such as (i) the challenges that decision makers have to deal with different time frames of product development (longterm technology development versus short-term applications) as discussed by Sommer et al. (2015) and Cooper (2016); (ii) the importance of governance in Agile New Product Development (less explored in the literature); (iii) sustainable change in adapting the iterative nature of Agile within academic partners and regulatory agencies, more used to classical project management approaches.

\section{REFERENCES}

Beck, K., Beedle, M., Van Bennekum, A., Cockburn, A., Cunningham, W., Fowler, M., Grenning, J., Highsmith, J., Hunt, A., Jeffries, R. and Kern, J. (2001), Manifesto for Agile software development.

Carvalho, M., Fleury, A. and Lopes, A.P. (2013), "An overview of the literature on technology roadmapping (TRM): Contributions and trends", Technological Forecasting and Social Change, Vol. 80 No. 7, pp. 1418-1437. https://doi.org/10.1016/j.techfore.2012.11.008

Carvalho, R. Q., Santos, G.V. and Barros Neto, M.C. (2013), "R\&D+ i strategic management in a public company in the Brazilian electric sector", Journal of Technology Management \& Innovation, Vol. 8 No. 2 , pp. 235-250. http://dx.doi.org/10.4067/S0718-27242013000200019

Chuang, S.W., Luor, T. and Lu, H.P. (2014), "Assessment of institutions, scholars, and contributions on Agile software development (2001-2012)", Journal of Systems and Software, Vol. 93, pp. 84-101. https://doi.org/10.1016/j.jss.2014.03.006

Conboy, K. (2009), "Agility from first principles: Reconstructing the concept of agility in information systems development", Information Systems Research, Vol. 20 No. 3, pp. 329-354. https://doi.org/10.1287/isre.1090.0236

Conforto, E.C., Amaral, D.C., da Silva, S.L., Di Felippo, A. and Kamikawachi, D.S.L. (2016), "The agility construct on project management theory" International Journal of Project Management, Vol. 34 No. 4 , pp. 660-674. https://doi.org/10.1016/j.ijproman.2016.01.007

Conforto, E.C., Salum, F., Amaral, D.C., da Silva, S.L. and de Almeida, L.F.M. (2014), Can Agile project management be adopted by industries other than software development?", Project Management Journal, Vol. 45 No. 3, pp. 21-34. https://doi.org/10.1002/pmj.21410

Conforto, E.C. and Amaral, D.C. (2016), "Agile project management and stage-gate model-A hybrid framework for technology-based companies", Journal of Engineering and Technology Management, Vol. 40, pp. 1-14. https://doi.org/10.1016/j.jengtecman.2016.02.003

Cooper, R.G. (2014), “What's next?: After stage-gate", Research-Technology Management, Vol. 57 No. 1, pp. 20-31. https://doi.org/10.5437/08956308X5606963

Cooper, R.G. (2016), “Agile-Stage-Gate Hybrids: The Next Stage for Product Development Blending Agile and Stage-Gate methods can provide flexibility, speed, and improved communication in new-product development", Research-Technology Management, Vol. 59 No. 1, pp. 21-29. https://doi.org/10.1080/08956308.2016.1117317

Cooper, R.G. and Sommer, A.F. (2016a), "The Agile-Stage-Gate Hybrid Model: A Promising New Approach and a New Research Opportunity", Journal of Product Innovation Management, Vol. 33 No. 5, pp. 513-526. https://doi.org/10.1111/jpim.12314

Cooper, R.G. and Sommer, A.F. (2016b), "Agile-Stage-Gate: New idea-to-launch method for manufactured new products is faster, more responsive", Industrial Marketing Management, Vol. 59, pp. 167-180. https://doi.org/10.1016/j.indmarman.2016.10.006

Cooper, R.G. (2017), "Idea-to-Launch Gating Systems: Better, Faster, and More Agile: Leading firms are rethinking and reinventing their idea-to-launch gating systems, adding elements of Agile to traditional Stage-Gate structures to add flexibility and speed while retaining structure", Research-Technology Management, Vol. 60 No. 1, pp. 48-52. https://doi.org/10.1080/08956308.2017.1255057

Cooper, R.G. and Sommer, A.F. (2018), "Agile-Stage-Gate for Manufacturers: Changing the Way New Products Are Developed Integrating Agile project management methods into a Stage-Gate system offers both opportunities and challenges", Research-Technology Management, Vol. 61 No. 2, pp. 17-26. https://doi.org/10.1080/08956308.2018.1421380

Di Silvestre, M.L., Favuzza, S., Sanseverino, E.R. and Zizzo, G. (2018), "How Decarbonization, Digitalization and Decentralization are changing key power infrastructures", Renewable and Sustainable Energy Reviews, Vol. 93, pp. 483-498. https://doi.org/10.1016/j.rser.2018.05.068

Dingsøyr, T., Nerur, S., Balijepally, V. and Moe, N.B. (2012), "A decade of Agile methodologies: Towards explaining Agile software development", Journal of Systems and Software, Vol. 85 No. 6, pp. 1213-1221. https://doi.org/10.1016/j.jss.2012.02.033

Dybå, T. and Dingsøyr, T. (2008), "Empirical studies of Agile software development: A systematic review. Information and software technology, Vol. 50 No. 9-10, pp. 833-859.

https://doi.org/10.1016/j.infsof.2008.01.006 
Fitzgerald, B., Stol, K.J., O’Sullivan, R. and O’Brien, D. (2013), May. “Scaling Agile methods to regulated environments: An industry case study". In Proceedings of the 2013 International Conference on Software Engineering (pp. 863-872). IEEE Press. https://doi.org/10.1109/ICSE.2013.6606635

Grimheden, M.E. (2013), “Can Agile methods enhance mechatronics design education?”, Mechatronics, Vol. 23 No. 8, pp. 967-973. https://doi.org/10.1016/j.mechatronics.2013.01.003

Giorgadze, L., Alibiev, D., Chirico, G.D. and Kazhikenova, A.S. (2017), Minimization of product defects by the means of implementing correct test pyramid in the software development process.

Ghobakhloo, M. and Azar, A. (2018), "Business excellence via advanced manufacturing technology and leanAgile manufacturing”, Journal of Manufacturing Technology Management, Vol. 29 No. 1, pp. 2-24. https://doi.org/10.1108/JMTM-03-2017-0049

Karlstrom, D. and Runeson, P. (2005), "Combining Agile methods with stage-gate project management", IEEE software, Vol. 22 No. 3, pp. 43-49. https://doi.org/10.1109/MS.2005.59

Leite, M. and Braz, V. (2016), "Agile manufacturing practices for new product development: industrial case studies”, Journal of Manufacturing Technology Management, Vol. 27 No. 4, pp. 560-576. https://doi.org/10.1108/JMTM-09-2015-0073

MacCormack, A., Crandall, W., Henderson, P. and Toft, P. (2012), "Do you need a new product-development strategy?", Research-Technology Management, Vol. 55 No. 1, pp. 34-43. https://doi.org/10.5437/08956308X5501014

Pikkarainen, M. and Passoja, U. (2005), June. “An approach for assessing suitability of Agile solutions: A case study”. In International Conference on Extreme Programming and Agile Processes in Software Engineering (pp. 171-179). Springer, Berlin, Heidelberg. https://doi.org/10.1007/11499053_20

Reich, Y. and Subrahmanian, E. (2017), “The PSI matrix-A framework and a theory of design”. In: Proceedings of the 21st International Conference on Engineering Design (ICED17), Vol. 7: Design Theory and Research Methodology, Vancouver, Canada, 21.-25.08.2017.

Ries, E. (2011), The lean startup: How today's entrepreneurs use continuous innovation to create radically successful businesses. Crown Books.

Ries, E. (2017), The Startup Way: How Modern Companies Use Entrepreneurial Management to Transform Culture and Drive Long-term Growth. Penguin Random House LLC, New York.

Schön, E.M., Escalona, M.J. and Thomaschewski, J. (2015), "Agile values and their implementation in practice", IJIMAI, Vol. 3 No. 5, pp. 61-66. https://doi.org/10.9781/ijimai.2015.358

Serrador, P. and Pinto, J.K. (2015. Does Agile work?-A quantitative analysis of Agile project success. International Journal of Project Management, 33(5), pp. 1040-1051. https://doi.org/10.1016/j.ijproman.2015.01.006

Smith, P.G. (2008), “Change: Embrace it, don’t deny it”, Research-Technology Management, Vol. 51 No. 4 , pp. 34-40. https://doi.org/10.1080/08956308.2008.11657512

Sommer, A.F., Hedegaard, C., Dukovska-Popovska, I. and Steger-Jensen, K. (2015), "Improved product development performance through Agile/Stage-Gate hybrids: The next-generation Stage-Gate process?", Research-Technology Management, Vol. 58 No. 1, pp. 34-45. https://doi.org/10.5437/08956308X5801236

Sagar, A. D. and Van der Zwaan, B. (2006), "Technological innovation in the energy sector: R\&D, deployment, and learning-by-doing", Energy Policy, Vol. 34 No. 17, pp. 2601-2608. https://doi.org/10.1016/j.enpol.2005.04.012

Subrahmanian, E., Eckert, C., McMahon, C. and Reich, Y. (2017), "Economic development as design: Insight and guidance through the PSI framework", In: Proceedings of the 21st International Conference on Engineering Design (ICED17), Vol. 1: Resource-Sensitive Design | Design Research Applications and Case Studies, Vancouver, Canada, 21.-25.08.2017.

Tura, N., Hannola, L. and Pynnönen, M. (2017), "Agile Methods for Boosting the Commercialization Process of New Technology”, International Journal of Innovation and Technology Management, Vol. 14 No. 03, p. 1750013. https://doi.org/10.1142/S0219877017500134

Waldron, K. (2017), "Implementing a collaborative working environment using Agile: the lexisnexis experience. Legal Information Management, Vol. 17 No. 1, pp. 16-19. https://doi.org/10.1017/S147266961700007X 